\title{
FAMILY'S RESILIENCE IN CAREGIVING ELDERLY WITH DEMENTIA: A SYSTEMATIC REVIEW
}

\author{
Anung Ahadi Pradana ${ }^{1}$, Rohayati ${ }^{1}$ \\ Department of Nursing, STIKes Mitra Keluarga, Bekasi, Indonesia
}

Correspondence email: ahadianung@gmail.com

\begin{abstract}
Objective: Dementia patients have complex needs that may become a burden to those who caregive them. They are treated at home by family members due to financial limitations and lack of support from health services. Therefore, the measurement of self-resilience in caregivers needs special attention from professionals. Method: This study used a systematic review method from 4 databases consisting of the CINAHL, ProQuest, PubMed, and Google Scholar between 2015 till 2020; 17 articles were considered to meet the inclusion criteria. Results: Caregiver of elderly with dementia has a tendency to experience burdens that affect the quality of the care performed. The level of resilience that caregivers have can help reduce the level of burden they experience and improve their quality of life. Conclusions: Social support and formal support by health workers for caregivers have a significantly positive effect in increasing the level of resilience of caregivers.
\end{abstract}

Keywords: Caregivers, Dementia, Family, Psychological Resilience

\section{Introduction}

Dementia has become a global disease that affects around 50 million people with 7.7 million new patients every year in the world, with $60 \%$ of whom live in developing countries. The number of dementia patients is estimated to increase to 82 million in 2030 and 152 million in $2050 .{ }^{1}$ Alzheimer Indonesia ${ }^{2}$ states that the number of dementia patients in Indonesia in 2010 were 1.2 million people, while it is estimated that in 2020 it will be 2 million and become 4 million in 2050 .

Most of dementia patients are treated at home by family members due to financial limitations and lack of support from health services. $^{2}$ The full dependence needed by dementia patients can sometimes be a trigger for physical and emotional exhaustion from family members. Behavioral problems and psychological symptoms that occur in dementia patients as well as socio-demographic factors and psychological factors from the family of

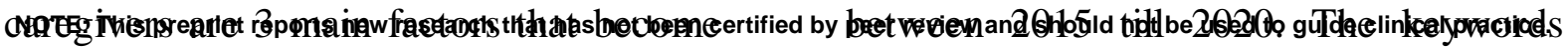

challenges in providing care by families. ${ }^{3}$ The burden experienced by the caregiver can be influenced by the level of selfresilience. $^{4}$

Resilience is a process in which individuals exhibit positive adaptation despite exposure to adverse life events, such as a diagnosis of dementia. ${ }^{4}$ These subjective measures can be biased by people's tendency to overestimate their resilient abilities or underestimate it in response to conditions such as depression. Caregivers who consider themselves highly resilient are often not tough and vice versa. ${ }^{5}$ Therefore, the measurement of self-resilience in caregivers needs special attention from professionals.

\section{Method}

This study was a systematic review. The following databases were searched in July 2020: Cumulative Index to Nursing and Allied Health Literature (CINAHL), ProQuest, PubMed, and Google Scholar 
medRxiv preprint doi: https://doi.org/10.1101/2021.06.16.21259058; this version posted June 20, 2021. The copyright holder for this preprint (which was not certified by peer review) is the author/funder, who has granted medRxiv a license to display the preprint in perpetuity.

It is made available under a CC-BY-NC-ND 4.0 International license .

used were a combination of "resilience", "elderly", "family", and "caregiver". Studies were included if (1) articles in English, (2) qualitative/quantitative research, (3) articles about the family's resilience on caregiving older adults with dementia. Exclusion criteria consisted of (1) articles in another language, (2) articles conducted in review article, (3) main caregiver is not family.

\section{Results}

From a total of 127 articles, 17 articles were considered to meet the inclusion criteria and passed the screening process using the PRISMA diagram (Diagram 1).

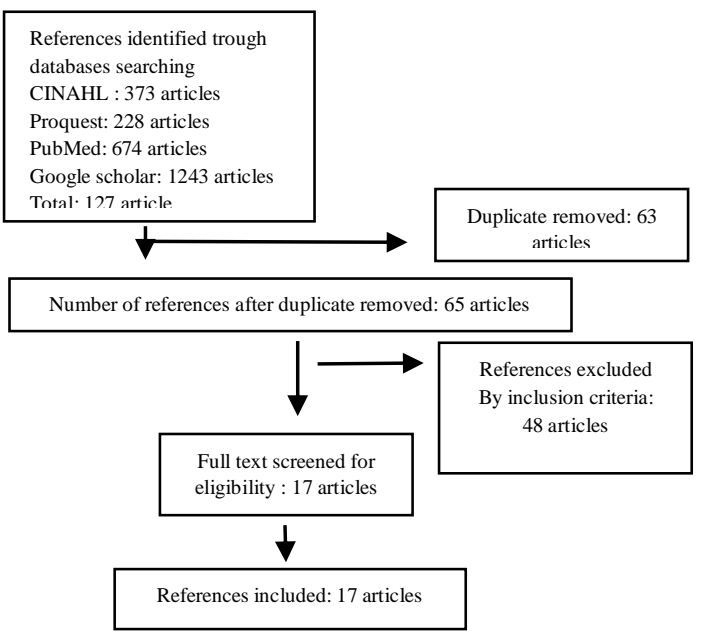

Figure 1 PRISMA Diagram

Based on 17 journal articles obtained, 8 articles used qualitative methods, 8 articles used cross-sectional quantitative methods, and 1 other article used mixed methods. The critical review that was carried out followed the Critical Appraisal Skills Program (CASP) guidelines from Cochrane, 17 selected articles were analyzed using the RobVis's Tracking

\section{Discussions}

Caregivers for older adults with dementia experience a relatively high burden, especially in the face of family dynamics, isolation, financial struggles, seeking respect, and acceptance. ${ }^{6}$ Research shows that the severity of dementia level condition experienced by elderly is
Media to obtain the Risk of Bias extraction results as listed in Figure 2.
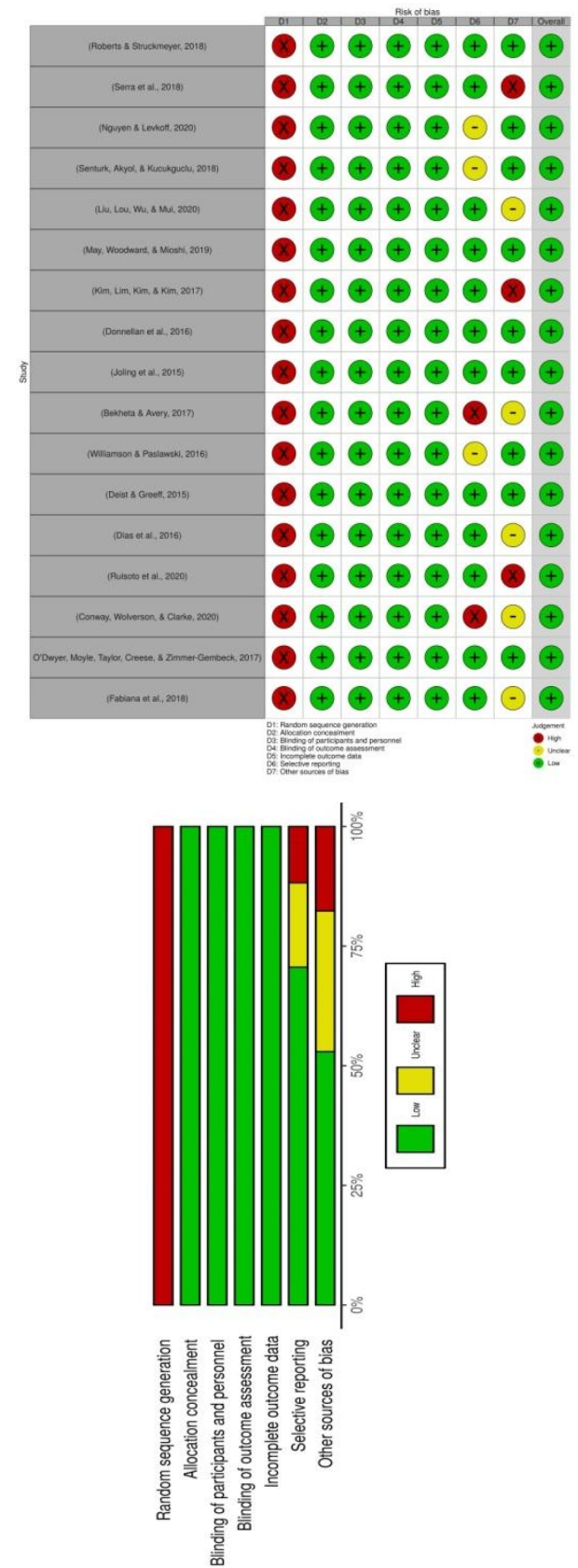

Figure 2 Risk of Bias

directly proportional to the burden of caregiving experienced by the family. This is exacerbated by an increase in caregiving hours, a bad relationship between caregivers and elderly. ${ }^{7}$ The increased burden of caregivers experienced can increase the risk of abuse in elderly. 
Caregiver's burden can be reduced by increasing the level of resilience of the caregiver which can be done by providing social support and formal support for the caregiver, and helping the caregiver develop effective coping techniques. ${ }^{8}$ Caregiver's resilience can improve family adaptation patterns to dementia problems experienced by elderly. ${ }^{9}$ The level of caregivers' resilience is influenced by several factors including internal and external factors. Internal factors include demographic factors from the family, personal beliefs, caregiving commitment, and the caregivers' coping ability in dealing with adversity. Meanwhile, external factors include cultural background, belief systems, family economic status, communication processes in the family, stress experienced by the family, social support, problematic behavior of elderly with dementia, and pressure from the community. ${ }^{10-12}$

Research shows that the social support things are often viewed differently by caregivers. Caregivers consider that support from family is not very influential because the assistance provided is relatively low compared to support from friends, especially those who also experience the same thing. The available social support should focus on internal/external factors that can increase resilience to caregivers. ${ }^{13}$

Resilient condition is a subjective response experienced by each caregiver in facing adversity that appears. Research conducted by Bekheta \& Avery ${ }^{14}$ shows that families perceive that resilience is identified as the ability to survive from risk factors to being carers, which include stress, frustration, lack of social support, fatigue, and negative feelings (sadness, anger). Other factors related to the caregiver's view of resilience include being considered a life goal, perspectives, and resources for caregivers. ${ }^{4}$
For spouses who are carers, resilience is often described as a continuous process that helps them maintain couplehood, a sense of togetherness, and reciprocity in their relationship. ${ }^{15}$ Many caregivers consider resilient conditions as a value, a resource or a result of being caregivers. ${ }^{16}$ Other studies have shown that resilient caregivers have a high quality of life, low depressive symptoms, and are able to care for elderly with relatively severe dementia conditions. $^{17}$

\section{Conclusions}

Caregiver of elderly with dementia has a tendency to experience burdens that affect the quality of care performed. The level of resilience that caregivers have can help reduce the level of burden they experience and improve their quality of life. Social support and formal support by health workers for caregivers have a significantly positive effect in increasing the level of resilience of caregivers.

\section{Acknowledgements}

This work is supported and funded by STIKes Mitra Keluarga.

\section{References}

1. World Health Organization. Dementia Fact sheet. WHO. 2017. p. $1-4$.

2. Alzheimer Indonesia. Demensia [Internet]. 2017. Available from: https://alzi.or.id/perkembanganpenelitian-demensia-alzheimer/

3. C.-Y. Chiao, Wu S, Hsiao C-Y. Caregiver burden for informal caregivers of patients with dementia : A systematic review. Int Nurs Rev. 2015;62(110):340-50.

4. Zhou Y, Ishado E, Hara AO, Borson S, Sadak T. Developing a Unifying Model of Resilience in Dementia Caregiving : A Scoping Review and Content Analysis. J Appl Gerontol. 2020;1-12.

5. Williamson T, Paslawski T. Resilience in dementia: Perspectives 
medRxiv preprint doi: https://doi.org/10.1101/2021.06.16.21259058; this version posted June 20, 2021. The copyright holder for this preprint (which was not certified by peer review) is the author/funder, who has granted medRxiv a license to display the preprint in perpetuity.

It is made available under a CC-BY-NC-ND 4.0 International license

of those living with dementia. Can J Speech-Language Pathol Audiol. 2016;40(1):1-15.

6. Roberts E, Struckmeyer KM. The Impact of Respite Programming on Caregiver Resilience in Dementia Care : A Qualitative Examination of Family Caregiver Perspectives. Inq J Heal Care Organ Provision, Financ. 2018;55:1-11.

7. Serra L, Contador I, Fernándezcalvo B, Ruisoto P, Jenaro C, Flores $\mathrm{N}$, et al. Resilience and social support as protective factors against abuse of patients with dementia: A study on family caregivers. Int $\mathbf{J}$ Geriatr Psychiatry. 2018; (August 2017):1-7.

8. Senturk SG, Akyol MA, Kucukguclu O. The Relationship between Caregiver Burden and Psychological Resilience in Caregivers of Individuals with Dementia. Int J Caring Sci. 2018;11(2):1223.

9. Kim GM, Lim JY, Kim EJ, Kim SS. A model of adaptation for families of elderly patients with dementia : focusing on family resilience. Aging Ment Health [Internet]. 2017;7863(July). Available from: http://dx.doi.org/10.1080/13607863. 2017.1354972

10. Deist M, Greeff AP. Living with a parent with dementia: A family resilience study. Dementia. 2015;0(0):1-16.

11. Joling KJ, Windle G, Dröes R-M, Huisman M, Hertogh CMPM, Woods RT. What are the essential features of resilience for informal caregivers of people living with dementia ? A Delphi consensus examination. Aging Ment Health. 2015;(December).

12. Nguyen T, Levkoff S. "What Will Come Will Come ": The Journey of Adjustment and Acceptance on the Path of Dementia Care Among Vietnamese Family Caregivers. Qual Health Res. 2020;0(0):1-17.

13. Dias R, Simões-neto JP, Santos RL, Fernanda M, Sousa B De, Baptista AT, et al. Caregivers ' resilience is independent from the clinical symptoms of dementia. Arq Neuropsiquiatr. 2016;74(12):96773.

14. Bekheta AK, Avery JS. Resilience from the Perspectives of Caregivers of Persons with Dementia. Arch Psychiatr Nurs [Internet]. 2017;(September). Available from: http://dx.doi.org/10.1016/j.apnu.201 7.09.008

15. Conway L, Wolverson E, Clarke C. Shared Experiences of Resilience Amongst Couples Where One Partner Is Living With Dementia A Grounded Theory Study. Front Med. 2020;7(June):1-8.

16. O'Dwyer ST, Moyle W, Taylor T, Creese J, Zimmer-Gembeck M. In Their OwnWords: How Family Carers of People with Dementia Understand Resilience. Behav Sci (Basel). 2017;7(57).

17. Pessotti CFC, Fonseca LC, Tedrus GMDAS, Laloni DT. Family caregivers of elderly with dementia: Relationship between religiosity, resilience, quality of life and burden. Dement Neuropsychol. 2018;12(4):408-14. 